European Society for Paediatric Haematology and Immunology (ESPHI)

\section{3}

CLINICAL ASSOCIATIONS WITH SS-A ANTIBODIES IN CHILDREN. Rebecca Hertzberger-ten Cate. Lisette W.A. van Suijlekom-Smit, Herbert Hooijkaas and Joop P. van de Merwe. Departments of Pediatrics and Immunology, Erasmus University and University Hospital/Sophia Children's Hospital, Rotterdam.

Antibodies to SS-A (Ro) are associated with primary Sjögren's syndrome, Systemic Lupus Erythematosus (SLE), subacuie cutaneous LE with of without C2 deficiency and neonatal lupus. They can also be found in up to $1 \%$ of healthy individuals. Antibodies to SS-A are rare in childhood.

We retrospectively looked at clinical pictures of all children who had circulating SS-A antibodies determined with immunodiffusion (IF) and ELISA techniques in the year 1993. SS-A antibodies were detected in nine children, six giris and three boys. The majority of children were from Caucasian origin, two were Hindustan and one negroid. One of the patients was a neonate with a congenital heart-block (mother ANA and SS-A positive without clinical symptoms). In the other children the age of onset of clinical symtoms varied from 5 to 12 years. Two patients were diagnosed as SLE with secondary Sjögren's syndrome, two as SLE with nefritis (one with restrictive lung disease), three as undefinod autoimmune disease (one with a chronic uveitis) and two hoys with fatigue, myopathy and parotic swellling (Raynaud's phenomenon in one). In all patients fatigue was a predominant symptom. None of the patients complained of dry eyes. Antinuclear antibodies were positive in seven children, antibodies to dsDNA in four. In conclusion, SS-A antibodicis are associated with a limited number of clinical syndromes and may he present in spite of a negative ANA-IF test. Longtime follow-up is indicated as it may take years for autoimmune diseases to fully develop.

\section{4}

HYPERTROPHIC OSTEOARTHROPATHY IN CHILOREN WITH LEUKEMIA

G. Kardos, A.H.M. Taets van Amerongen. A.J.P. Veerman

Free University Hospital, Dept. Pediatrics and Radiology, Amsterdam, The Netherlands

Bone lesions are frequently encountered in children with leukemia as part of their disease or occasionally as consequence of therapy. While leukemic infiltration is a well known cause of bone pain in children, avascular necrosis and osteoporosis can also be responsible for these complaints.

The authors present two children with an unusual cause of bone pain in childhood leukemia, hypertrophic osteoarthropathy (HOA). This condition is well known in adults, but is rarely seen in children. The most frequently associated conditions in children are chronic lung liver or heart disease and sometimes malignant or benign tumors. In a child with acute non-lymphoid leukemia (ANLL) FAB type M7 and in a child with child with acuith common acute lymphoid leukemia (ALL) . bone pain developed. The radiographs showed cortical thickening and periosteal new bone formation along the diaphyses of the long bones. Bone scintigraphy remained regalive Mat showed no signs of residual leukemic inithration. Bolh children were in remission at the ime of dection res the bone lesions, and did nor have any signs of chronic infection. Approximately three months later however - although the bone pain disappeared - the child with ANLL developed a myelodysplastic syndrome (MOS) and the patient with ALL a partial relapse with $12 \%$ blasts in the bone marrow. The occur. rence of HOA in children with leukemia, both ANLL and ALL. should instigate repeated bone marrow investigation since it might herald MDS or relapse.

\section{5}

"PRIMARY CUTANEOUS MALIGNANT B-Cell NHL IN A INFANT"

Luigi Nespoli, Marco Montalbetti, Maddalena Marinoni, Marzia Bonato. Pediatric Division - Department of Histopathology - II Facoltà di Medicina e Chirurgia - I - 21100 - Varese - Italy.

Cutaneous malignant Lymphoma in infancy is rare. The majority of the se tumors present nonB - nonT cell phenothype. Recently, we encountered an infant with cutaneous malignant Lymphona, wich was a B-cell tumor in origin. The patient was a 23 month old female and she came to our Clinic on July, 1992. Seven months previously, her mother noticed a tumor on the back wich was considered a sebaceous cyst and ticed a tunor on the back wich was considered a sebaceous cyst and
then an angions. Her general conditions was good. Since the lesion then an angioms. Her general conditions was good. Since the lesion violet, dome-shaped, indolent and movable nodular cutaneous tumor violet, dome-shaped, indolent and movable nodular cutaneous tumor
was confined to a circunscribed area of the skin, in left subscapowas confined to a circunscribed area of the skin, in left subscapolar region, about $3 \times 2 \mathrm{~cm}$ in size. Systemic lymphadenopathy and sple-
nomegaly were not present. The tumor was radically removed and the
histological diagnosis vas: High grade non Hodgkin, diffuse lymphoma, histological diagnosis was: High grade non Hodgkin, diffuse lymphoma, mulation. The neoplastic infiltrate react with CD 45R, CD 45RA, CD $20, \mathrm{CD} 43$ and failed to react with $\mathrm{CD} 30, \mathrm{CD} 45 \mathrm{RO}$, confirming the B cell phenotype. Bone marrow aspirate revealed no evidecence of involvement by tumor cells. After staging investigations, following Murphy's criteris, the patient was treated with two blocks of therapy, according to AIEOP Hon Hodgkin Lymphoma 92 Protocol (DEXA, MTX-
MD, IFO, VP16, ARA-C + DRXA, CPM, MTX - MD, ADR). After 19 months, the $r e$ is no evidence of local recurrence or dissemination.

\title{
$\Delta 376$
}

Francesco Schettini, Rosa Penza, Paola Giordano, Giovanni c. Del Vecchio, Gabriella Aceto, Maria Altomare, Domenico De Mattia. DETERMINATTON OF vOn WILLEBRAND FACTOR AND FACTOR XIII IN CHILDREN WITH SCHONLEIN HENOCH SYNDROME. Dipartimento di Biomedicina dell'Età Evolutiva - University of Bari - Italy.

In 16 children ( $7 \mathrm{M}$ and $9 \mathrm{~F}$, aged between 4 and 11 years) with Schonlein Henoch Symdrome (SHS) at the onset, we have studied the levels of von willebrand Factor Antigen ( $v w f: A g$ ) and Factor XIII activity (F XIII) in relation to the severity of clinical symptoms and the immunological parameters: IgA, C3, C4 and circulating imnune complex (CIC). Arthral, abdominal and renal symptoms (except purpura) were scored from 0 to 3 and their mean values resulted respectively $1 \pm 0,82 ; 1,13 \pm 0,96 ; 1,38 \pm 1,26$ (total: $3,5 \pm 1,59$ ). The vwf: $\mathrm{Ag}$ resulted increased in 7 patients, the F XIII resulted decreased in 6 . In all children we found high levels of IgA, while the $\mathrm{C} 3$ and $\mathrm{C4}$ levels were normal.The CIC were elevated in 11.The total clinical score was positively correlated with vWf:Ag, IgA and CIC $(p<0.05)$. The abdominal score was positively correlated with vwf: Ag $(p<0.05)$; while the renal one with vWf:Ag $(p<0.05)$ and CIC $(p<0.001)$

Lastly vWf was correlated with IgA and CIC $(p<0.05)$ and as in other systemic vasculites its level was increased in the acute phase of SHS probably in reference to immunomediated endothelial cell damage. In conclusion vWF levels are a good marker of SHS severity.

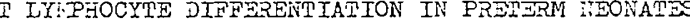
Nadejüa A. Tomuorova, Vladimir M. Studenikin, Alla V. Sarakutsa, Aronil N. Partenadze, Natalia K. Bresina, Deparinents o Haematology and iNeonatology, RAis Institute of raeciatrics, Moscow, Russia

Vie have defired $T$ lymphocyte (lph) membrane receptors (Rc) and glucocorticoid receptors (GR) in peripheral blood of 40 neonates with 31-36 weeks gestational age (GA) and in cord blood of 42 term infants, using monoclonal antibodies (Ortho Diagnostic Systems, USA), Lippdies are presented in the table.

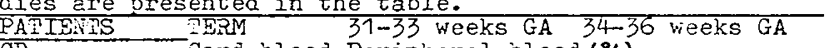

CD Cord blood Peripheral blood (\%)

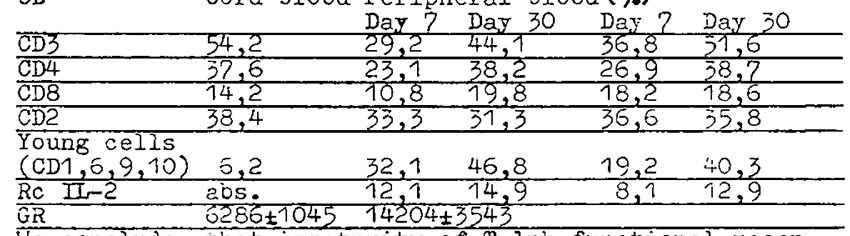

Se conclude, that inmaturity of $T$ lph functional receptors can be the basis of clinical innune deficiency.

378

ICF SYNDROME

Corry Weemaes ${ }^{1}$, Dominique Smeets ${ }^{2}$, Jan Bakkeren', Ineke v.d. Burgt ${ }^{2}$. Department of Pediatrics ${ }^{1}$ and Human Genetics ${ }^{2}$, University Hospital Nijmegen St Radboud, Nijmegen, The Netherlands.

ICF syndrome (Immunodeficiency, Centromeric instability, in particular of chromosomes 1 and 16 and Facial dysmorphisms) was described in 1988 by Maraschio et al. (J Med Genet 25:173-180).

Here we present another case of ICF syndrome. The boy was bom at 38 weeks, small for gestational age $(2055$ gram, $45 \mathrm{~cm})$. During the first year he had a failure to thrive and a slight psychomotor retardation. At the age of 10 months, he suffered from RS bronchiolitis. Immunological studies revealed an agammaglobulinaemia (all immunoglobulins were absent). B cells were normal, as were $\mathrm{T}$ cell markers $\left(\mathrm{CD}_{2} 58 \%, \mathrm{CD}_{3} 56 \%, \mathrm{CD}_{4} 36 \%, \mathrm{CD}_{8} 17 \%\right)$. In vitro responses of peripheral blood cells to PHA and PWM were normal. He had a typical face. Cytogenetic studies revealed a normal $46 \mathrm{XY}$ male karyotype, although half of the cells showed alterations (e.g. gaps, breaks, translocations, centromeric fusions, multiradial figures) in the centromeric regions of chromosomes 1 and 16. During immunoglobulin substitution he did not suffer from infection but he ceased growing, probably due to malabsorption.

Untill now, 15 patients with ICF syndrome are recognized. All but one had facial anomalies. All had immunodeficiency varying from IgA deficiency to SCID. A review of these patients will be given. 